\title{
$\$$ Research Square

\section{8-year post operative survival after penile prothesis implantation: Less than expected perioperative risk.}

Hamed Elgendy ( $\square$ helgendy70@gmail.com )

Al Wakrah Hospital, Hamad Medical Corporation

Walaa Hassan

Al Wakrah Hospital, Hamad Medical Corporation

Ibrahim Alnadhari

Al Wakrah Hospital, Hamad Medical Corporation

Ahmad Shamsodini

Al Wakrah Hospital, Hamad Medical Corporation

Abdulla Al Ansari

HAMAD General Hospital, Hamad Medical Corporation

\section{Research Article}

Keywords: Penile prosthesis, mortality, HbA1C, testosterone, outcome.

Posted Date: May 5th, 2021

DOI: https://doi.org/10.21203/rs.3.rs-457922/v1

License: (c) (1) This work is licensed under a Creative Commons Attribution 4.0 International License.

Read Full License 


\section{Abstract}

Background: Penile prosthesis implantation (PPI) is the surgical correction of patients with erectile dysfunction. These patients usually present with multiple co-morbidities such as cardiovascular, cerebral or organ impairment.

Objectives: The primary objective of this study is to investigate the survival patterns of the study subjects after PPI, perioperative complications, length of hospital stay and Intensive Care Unit (ICU) admission. The next objective is to analyse the risk factors that contributed to their mortality.

Methods: In this observational study, a total of 109 males subjects were enrolled who had all undergone PPI in our institute. They were assigned into either of the two groups -based on their median age-where group 1 consisted of patients $\geq 60$ years old, and group 2 consisted of patients $<60$ years old.

Results: In group1, individuals exhibited: ASA score equal to or higher than 3, more than three comorbidities and were prescribed to anti-coagulants, $\mathrm{P}<0.0001, \mathrm{P}=0.018, \mathrm{P}<0.0001$ respectively. More than half of patients in group-1 had poor diabetic control (HbA1C $\geq 7 \%)$. Majority of patients had insertion of the 3-piece Inflatables, Boston/Coloplast, i.e., group-1 was 37/55 (67.3 \%), while in group-2, was, $35 / 54(64.81 \%)$. The majority of patients in both groups had received spinal anaesthesia with minimal surgical complications. None of the enrolled patients had received inotropic support perioperatively and none of them were admitted to the ICU. There were no perioperative or 60-day mortalities. However, there were two patients in each group- a total of four pateints that had expired. The clinical characteristics of the four deceased patients includedmultiple co-morbidities, being overweight and exhibited major vascular risk diseases or surgeries. Three of the deceased patients exhibited high preoperative $\mathrm{HbA} 1 \mathrm{C}$ readings, however, all four patients showed a low preoperative testosterone levels. But it was noted that all four of these pateints they had normal ejection fraction. Three of those patients survived for more than six years postoperatively except for one patient who had expired three months postoperatively, mostly due to a vascular accident. Every patient was admitted for one day postoperatively and none of them were admitted to the ICU. A high preoperative systolic blood pressure, $\mathrm{P}$ $=0.028$ was significantly associated with mortalityAnd a low preoperative testosterone serum level, $\mathrm{P}=$ 0.040 was seen to be the independent risk factor for the patients overall survival.

Conclusion: PPI is considered a safe procedure in spite of the elderly individuals presenting with comorbidities. The risk of mortality is still possible due to the presence of those comorbidities, however the probability of it is far more likely to happen in the distant future- post-operatively. Addionally, the optimization of preoperative HTN is required and it can also be concluded that low testosterone levels are an independent risk factor for mortality.

\section{Introduction}

Penile prosthesis implantation (PPI) is the recommended treatment for patients with Erectile Dysfunction (ED) when all other forms of medical interventions fail (1), (2).ED has been defined as the inability to 
achieve or even maintain a rigid erection appropriately for satisfying sexual intercourse. This surgery attempts to aid those patients and thus improve their quality of their life (3). The potential surgical risks, preoperative counselling and expectations have already been explained in previous literatures (4),(5). ED is proportionally associated with arteriosclerosis process and cardiovascular events (6). This underlying medical condition is easily result in complications during stent procedures (7) and use of anti-coagulates which increased their risk status (8). Additionally, poor diabetes control is commonly associated with infection in patients with PPI, which needs to be to be monitored (9).

A limited number of past reports have studied the risk factors for patients that are more likely to survive on a short-term basis mainly due to a combination of co morbidities, for example: coronary artery disease, open-heart surgery, diabetes, vascular disease, history of stroke, and other chronic diseases such as hepatic and renal failure (10). Similarly, the associated risk with an underlying cardiovascular disease has also been investigated in a previous report (11).

At the present studies institution, the perioperative protocol included a standby booking of an ICU in selected patients with an ejection fraction (EF) of less than $40 \%$, subjects with a history of a cerebral stroke and severe pulmonary conditions, patients with ASA III status, obstructive sleep apnea, and history of significant invasive cardiovascular procedures.PPI was introduced over eight years ago at the present studies institution and as such, the risk of mortality and morbidity has been anticipated in such critical patients, particularly elderly subjects. Moreover, limited ICU beds have raised the concerns to be reserved for the highly required patients with illness.

Long term function of the prosthesis, i.e., for up to 15 years along with the outcome of post-hospital syndrome have been investigated in past studies (12), (13). However, the mortality rate of patients based on the risks imposed by anaesthesia, along with the risks involved during the perioperative period has not been extensively studied by past literature (10). This perioperative risk can occur to elderly subjects undergoing urology surgery that ranges from delirium (14) to postoperative disability (15) and ICU admission (16).

The aim of the present study was to investigate the: survival pattern of those subjects after PPI, perioperative complications, length of hospital stay and ICU admission as a primary objective. Our secondary objective was to analyse the risk factors which contributed to that mortality.

\section{Methods}

After getting our local institutional review board approval, 109 male patients who had underwent PPI at Al-Wakrah Hospital; Hamad Medical Corporation between January 1, 2012, and March 31, 2020, were included. We got approval of our ethical committee of the institutional IRB Medical Research Centre at HAMAD Medical Corporation, Qatar (MRC-01-20-387) before going for data collection.

\section{Waiving of patients 'informed consent was approved for this observational retrospective study by our Ethical IRB as above.}


The study was carried out under the principles of the Declaration of Helsinki.

The hospitals electronic medical record was reviewed in order to identify patients who match study defined criteria. Once the eligible patients were identified, The following variables were collected: age, body weight, height, body mass index, presence of any co morbidities, for instance; Coronary Artery Disease (CAD), Low Ejection Fraction (EF), Diabetes Mellitus (DM), Hypertension (HTN),cerebral stroke, liver, renal and pulmonary diseases. Intra-operative and post-operative variables were also collected, along with any surgical complications, type of prosthesis used in surgery, postoperative course, intensive care unit (ICU) admission, and length of hospital stay and postoperative survivals.

Additionally, laboratory investigations such as $\mathrm{HbA1C}$ - complete blood picture-renal and liver functions, coagulation profile, preoperative Prostate Specific Antigen (PSA). The patients testosterone levels was included in this study as well, together with commonly used drugs by the patient, such as: oral hypoglycaemic, insulin, anti-coagulants; aspirin, other anti-platelets; warfarin, clopidogrel. Additionally, the present study recorded the type of anaesthesia that was used on the patient, which was documented as: general anaesthesia, spinal or combined spinal epidural type anaesthesia. Survival analysis and risk factors associated with that outcome were analysed. We analysed the criteria of the deceased patients, dissected their associated risk factors and postoperative outcome. All consecutive patients were compared according to this cohort median's age and were assigned either into group $1: \geq 60$ years old and group 2:<60 years old.

\section{Surgical Procedure\& antibiotic administration}

The surgeries were performed by the senior surgeons of Al-Wakra hospital. Preoperatively, the patients were counselled regarding the control of their blood sugar and instructed to halt the use of their anticoagulant and antiplatelet medications, as per the patient's condition and advice of the anticoagulation clinic. The surgical procedure was carried out under spinal or general anaesthesia. Next, the clipping of the external genital hair was done, followed by external wash with chlorhexidine (17),(18). Intravenous antibiotics were started one hour before the incision in the form of vancomycin $1000 \mathrm{mg} / \mathrm{I} . \mathrm{V}$., two times/day, and gentamycin $80 \mathrm{mg} / \mathrm{l} . \mathrm{V}$., three times/day. Other alternatives for patients with impaired renal functioning was ceftriaxone $2 \mathrm{gm} / \mathrm{I} . \mathrm{V}$., once a day, and clindamycin $600 \mathrm{mg} /$ I.V. (19). Transverse penoscrotal incision was used for prosthesis placement and no touch technique was used to minimize the risk of infection(20). Intra-operatively, the corporal bodies were irrigated with mixture of $500 \mathrm{ml}$ of saline with five vials of rifampicin $600 \mathrm{mg}$ and gentamycin $80 \mathrm{mg}$ ampoules. The prosthesis with its components was immersed with the same antibiotics solutions (21). The types of penile prosthesis used include: three pieces inflatable penile prosthesis, two pieces inflatable penile prosthesis or malleable penile prosthesis. The reservoir was then inserted in the retiz space, in case of three pieces penile prosthesis insertion. And surgical drain was used only in some cases. Finally, the wound was closed in multiple layers.

\section{Statistics}


Descriptive statistics will be used to summarize all demographic data, clinical data, laboratory tests, intra operative data, postoperative course and outcomes. The normally distributed data and results were reported with mean and standard deviation (SD). Categorical data was summarized using frequencies and percentages.

Survival can be performed using Kaplan Meir Curve; risk factors can be identified by using Univariate Analysis and Multivariate Logistic Regression Analysis. All P values presented will be two-tailed, and $\mathrm{P}$ values $<0.05$ will be considered as statistically significant. All Statistical analyses will be done using statistical packages SPSS 22.0 (SPSS Inc. Chicago, IL) and Epi-info (Centers for Disease Control and Prevention, Atlanta, GA) software.

\section{Results}

A total of 109 male patients with ED were enrolled in this study and underwent PPI in our institute from 2012 to 2020. Clinical characteristics of our patients were analysed. They were assigned into two groups according to their median age, group $1: \geq 60$ years old and group $2 ;<60$ years old. The majority of patients in both groups were Qataris, i.e., in group-1 (39/55) 70.9\% and in group-2 (33/54) $61.1 \%$, the remaining subjects were expatriates. The percentages of an ASA score equal or higher than 3 , patients with more than three co morbidities and patients on anti-coagulants were significantly higher in group-1 in comparison to the patients in group-2 where $P<0.0001, P=0.018, P<0.0001$, respectively. Majority of patients in both groups had $\mathrm{BMI}<35$. More than half of patients in group- 1 had poor control of their blood glucose level (HbA1C $\geq 7 \%$ ). Patients in group-1 exhibited a higher percentage of the following morbidities: HTN, DM, renal, CNS strokes and use of chronic medications. However, they were statistically insignificant.

In group 1, a history of cancer surgery and/or active treatment with chemotherapy was noted in two cases that were diagnosed with prostate cancer. Similarly, one case in group 1 was diagnosed with the following types of cancers: brain tumor, oesophageal cancer and thyroid carcinoma. In group 2, one case was diagnosed with gastric carcinoma, ureteric transitional cell carcinoma, and Hodgkin lymphoma.Other laboratory variables had insignificant difference between the two groups as shown in Table-1.

\section{Perioperative variables and outcome}

The majority of patients in group-1 and group-2 had received spinal anaesthesia, (90.9\%), (92.6\%), $P$ $=0.483$, respectively. There were insignificant differences regarding the intra-operative fluid requirements, blood loss, surgical complications and postoperative haemodynamic parameters, and none of the patients in both groups had urethral injury. Majority of patients had insertion of the 3-piece Inflatables, Boston/Coloplast, where it was 37/55 (67.3\%) and35/54 (64.81\%) in group 1 and group 2, respectively. Whereas the semirigid type was inserted in 5/55 (9\%) and 9/54 (16.7 \%) in group 1 and group 2, respectively. Furthermore, the least percentage was for 2-piece inflatable: Ambicor type, which constituted $6 / 55,(10.9 \%), 4 / 54$ (7.4\%) in group 1 and group 2, respectively. None of these patients had received 
inotropic support perioperatively and none of the patients in the two groups were admitted to the ICU. Table 2 illustrates a comparison between the two groups in terms of the length of their hospital stay

\section{Survival of patients}

The cumulative survival is shown at figure1, and table 2 illustrates a comparison between the two groups in terms of their postoperative survival days where it can be noted that there were no perioperative or 60 day mortalities.

Detailed clinical characteristics of the four deceased patients who had multiple chronic co morbiditiesmostly ASA III, have major vascular risk diseases or surgeries- constituted as (4/112) $3.6 \%$, where two patients died in each group of this observational cohort. Three of them exhibited high preoperative $\mathrm{HbA} 1 \mathrm{C}$ readings, and all patients had a low level of preoperative testosterone and within normal level of PSA. Interestingly, they had normal ejection fraction of their pre-operative echocardiography and were categorized as overweight based on their BMI. None of these patients had cancer or oncology- related surgery or any surgical complications. All four of them had received spinal anaesthesia for their procedures during which they had a 3-piece Inflatable, Boston/Coloplast type of prosthesis inserted. These patients had minimal blood loss and no blood transfusions. Three of those patients have survived for more than six years postoperatively except one patient, who expired three months postoperatively mostly due to a vascular accident and his ASA III status. Only one patient of group- 2 exhibited postoperative prosthesis infection. Three patients experienced high risk non urological vascular surgeries. All patients were admitted for one day postoperatively-in the ward, and no ICU admission was required, as shown in Table-3.

\section{Risk Factors Associated with Postoperative mortality}

The risk potential variables associated with postoperative mortality were listed in (Table 4).

\section{Univariate analysis}

We used a univariate Cox's proportional hazard regression model to examine potential risk factors associated with a patient mortality. Univariate analysis revealed two potential risk factors at a statistical level of $\mathrm{P} \leq 0.05$. A high preoperative systolic blood pressure (SBP), $P=0.028$ and a low preoperative testosterone serum level, $P=0.040$ were significantly associated with mortality.

\section{Multivariate analysis}

Those potential predictors were further examined with multivariate analysis, lower preoperative testosterone, $\mathrm{P}=0.040$, (hazard ratio $[\mathrm{HR}]=1.174 ; 95 \%$ confidence interval $[\mathrm{Cl}]=1.007-1.368, \mathrm{P}=0.040$ ), was independent risk factor for the patient overall survival (Table 4).

\section{Discussion}


In this study we evaluated the mortality rates in patients with ED who underwent PPI at our institute for up to duration of eight years, and we observed an overall $3.6 \%$ of mortality- which had mainly occurred after prolonged duration of the perioperative period. Here, preoperative high systolic pressure was associated with mortality, and low preoperative testosterone level was an independent risk factor for mortality.

The deceased subjects were characterised with multiple co morbidities, poor control of diabetes and vascular disease risk procedures. There were no significant differences in length of hospital stay or ICU admission.

We aimed to analyse factors affecting mortality of those patients and examine how to optimize their preoperative health conditions and improve their survival. We observed in group1 that the elderly subjects were characterized by high morbidities and poor control of diabetes, which needed to be optimized preoperatively. This observation falls in line with previous studies that have highlighted that there are many risk factors have can be implicated in the development of ED in elderly patients, including smoking, poor diabetic control (9), hypertension (HTN) (22), coronary artery disease (23) and iatrogenic pelvic surgery (24). Previous studies found that coronary artery risk factors and hypertension are significantly associated with severe cases of erectile dysfunction (23), (22). Hence, optimization of HTN prior to surgery is crucial in our patients who have ASA III status and multiple co morbidities.

A quality improving project investigated the first postoperative month adverse event rates after PPI at a North American institute where it was discovered that only one patient died in 30 days post operatively, but they did not analyse long term mortality (10). However, in our study, there were no deaths at the first 60 postoperative days. Only four patients expired in this cohort with a survival follow-up for up to eight postoperative years. None of our patients were admitted to the ICU, which suggested a smooth perioperative course, and perfect anaesthesia management. Similar to our results, about $54 \%$ of patients had an ASA score equal or higher than 3 with numerous co morbidities (10).

Palma-Zamora and colleagues discovered that most of the surgical complications are infectious in their elderly subjects (10). In this study, we found only $3.6 \%$ of infection rate in spite of a tight infection control strategy and perioperative antibiotic coverage $(17),(18,19)$. When looking at past studies, Habous and colleagues showed that $\mathrm{HbA} 1 \mathrm{c}$ predicts increased risk of PPI infection, which could explain our infection rate (9).

There is an expected rise of the prevalence of diabetes in Qatar, i.e., from $16.7 \%$ in 2016 to $24.0 \%$ in 2050(25), which requires great efforts to be under control. A similar study in Saudi Arabia discovered that $71 \%$ of their patients exhibited $\mathrm{HbA} 1 \mathrm{c}$ greater than $7 \%$ and associated with the increasing severity of ED and IHD which augmented their morbidities (9). Even in North America, diabetics constituted more than twenty percent of subjects undergoing PPI (26).

There is a strong relationship between vasculopathy in patients with ED who are exhibiting either diabetes or Ischemic heart diseases (IHD). Benvenuti and his associates described that pathophysiology 
of diabetic ED is strongly attributed to vasculopathy more than neuropathic theory (27). A generalized pathophysiological process of occlusive atherosclerosis is the contributing factor that impairs arterial blood flow in patients with ED and IHD (28). Cardiovascular mortality increased among diabetic individuals whose $\mathrm{HbA} 1 \mathrm{c}$ exceeded $7 \%$ (29). The conclusions from these previous studies can thereby explain the degree of poor diabetic control with ED and the poor outcome regarding their cardiovascular risk and survival rate after surgery, in our study.

Taussig and colleagues (30), for the first time discovered an increase in PSA levels after cross-clamping in open heart surgery and Parlaktas et al., described its relation to this surgery (31). Another study attributed such rise in PSA levels to the pelvic ischemia and a relative infarction in the prostate (32). Interestingly, a group of scientists showed that a slight trauma to the prostate and urethral catheterization could initiate high PSA levels. A recent Korean study observed that total serum PSA levels within the reference range of young-aged men is inversely proportional to cardiovascular mortality, therefore indicating that PSA is a predictor for cardiovascular risk (33). However, this study did not observe high PSA levels in majority of our patients, but it was taken in consideration particularly in individuals who had cardiovascular co morbidities.

Epidemiological studies have proven that low testosterone levels can be associated with high cardiovascular risk (34), (35), (36), (37)and its optimization can reduce incidence of myocardial injury and death (38) which is parallel to our results. But a controversial debate about the safety of testosterone treatment along with randomized trials with sufficient numbers is required for such conclusion (39),(40), (41).

There have been many antagonizing replies for Dr Vigen and his colleagues' study which supported risk of testosterone therapy. These replies suggested serious flaws in both design and interpretation. Several researchers pointed out that the original data of Dr Vigen's Study, before various statistical adjustment, was supportive for use of testosterone therapy (42),(43) .

Our results are in line with a study conducted by Yeap et al.,(34)which concluded that low testosterone level is associated with a higher mortality as an independent risk factor. Moreover, in agreement with a large observational study with a long-term follow-up, they found that normalization of testosterone level had significantly associated with reduced mortality and cardiovascular events (38).

In both younger and older men, hypogonadism should be managed using testosterone therapy. Therefore, it appears to have no major concerns for treating young, healthy men with testosterone. Counselling should be suggested for asymptomatic, middle-aged and older men without a history of heart disease. Individuals with a recent myocardial injury, stroke, and uncontrolled heart failure are not good candidates for initiation of such a controversial therapy (35).

Anaesthesia role in our observational study was smooth and none of our patients required ICU admission. Majority of our cases had surgery under spinal anaesthesia. Other related studies discussed 
the use of dorsal penile nerve block which enhanced safe and effective early postoperative pain control (44), or using different local anaesthetics in this block (45).

This study provides short-term information on the complications, ICU admission, hospital stay, and longterm data about patient mortality rate. The results of this study can aid in providing information about the procedure during patient counselling to individuals that are seeking to undergo PPI.

When looking at the limitations of the present study, there are a few deficits that can be noted. This study was observational and retrospective in nature, with a relatively small number of participants. As a result, we could not correlate the lower physiologic reserves and perioperative outcomes. For future studies, it can be recommended to conduct a comprehensive prospective study.

\section{Conclusions}

Based on the result of the present study, it can be concluded that the surgery for penile prosthesis appears to be a safe option, even if the patient seeking the surgery is considered to be older in age. Additionally, the risk of mortality is still possible due to the presence of comorbidities, however the probability to happen is in the distant future-post-operatively. Furthermore, this surgery does not result in any form of prolonged hospital stay or ICU admission. Finally, it can also be concluded that low preoperative testosterone level is independent risk factor for mortality, and HTN should be optimized preoperatively.

\section{Declarations}

Ethics approval, guidelines and consent to participate:

We got approval of our ethical committee of the institutional IRB Medical Research Centre at HAMAD Medical Corporation, Qatar (MRC-01-20-387) before going for data collection. Waiving of patients 'informed consent was approved for this observational retrospective study by our Ethical IRB as above. The study was carried out under the principles of the Declaration of Helsinki.

Consent for publication: 'Not applicable'

Availability of data and materials: - The datasets used and/or analysed during the current study available from the corresponding author on reasonable request.

Competing interests: The authors declare that they have no conflicts of interest.

Funding: HAMAD Medical corporation through Qatar National Liberary (QNL) can support open access publication.

Authors' contributions: HE; WH; IA performed data collection, statistically analysis, writing manuscript and review the final form; $A S$ and $A A$ contributed in review and writing manuscript with critical analysis. 
Acknowledgements: to QNL when paying open access requirments.

Authors' information (optional)

\section{References}

1. Scott FB, Bradley WE, Timm GW. Management of erectile impotence. Use of implantable inflatable prosthesis. Urology. 1973 Jul;2(1):80-2.

2. Small MP, Carrion HM, Gordon JA. Small-Carrion penile prosthesis. New implant for management of impotence. Urology. 1975 Apr;5(4):479-86.

3. Conference NC. NIH Consensus Conference. Impotence. NIH Consensus Development Panel on Impotence. JAMA. 1993 Jul 7;270(1):83-90.

4. Narang GL, Figler BD, Coward RM. Preoperative counseling and expectation management for inflatable penile prosthesis implantation. Transl Androl Urol. 2017 Nov;6(Suppl 5):S869-S80.

5. Kovac JR. Informed consent for penile prosthesis surgery. Transl Androl Urol. 2017 Nov;6(Suppl 5):S881-S2.

6. Katsiki N, Wierzbicki AS, Mikhailidis DP. Erectile dysfunction and coronary heart disease. Curr Opin Cardiol. 2015 Jul;30(4):416-21.

7. Gupta AD, Streiff M, Resar J, Schoenberg M. Coronary stent management in elective genitourinary surgery. BJU Int. 2012 Aug;110(4):480-4.

8. Culkin DJ, Exaire EJ, Green D, Soloway MS, Gross AJ, Desai MR, et al. Anticoagulation and antiplatelet therapy in urological practice: ICUD/AUA review paper. J Urol. 2014 Oct;192(4):1026-34.

9. Habous M, Tal R, Tealab A, Soliman T, Nassar M, Mekawi Z, et al. Defining a glycated haemoglobin (HbA1c) level that predicts increased risk of penile implant infection. BJU Int. 2018 Feb;121(2):293300.

10. Palma-Zamora I, Sood A, Dabaja AA. 30-day adverse event rates following penile prosthesis surgery: an American College of Surgeons National Surgical Quality Improvement Program based evaluation. Transl Androl Urol. 2017 Nov;6(Suppl 5):S767-S73.

11. Lane-Cordova AD, Kershaw K, Liu K, Herrington D, Lloyd-Jones DM. Association Between Cardiovascular Health and Endothelial Function With Future Erectile Dysfunction: The Multi-Ethnic Study of Atherosclerosis. Am J Hypertens. 2017 Aug 1;30(8):815-21.

12. Chierigo F, Capogrosso P, Deho F, Pozzi E, Schifano N, Belladelli F, et al. Long-Term Follow-Up After Penile Prosthesis Implantation-Survival and Quality of Life Outcomes. J Sex Med. 2019 Nov;16(11):1827-33.

13. Kirshenbaum EJ, Nelson M, Hehemann MC, Kothari AN, Eguia E, Farooq A, et al. Impact of PostHospital Syndrome on Penile Prosthesis Outcomes: A Period of Global Health Risk. J Urol. 2019 Jan;201(1):154-9. 
14. Xue P, Wu Z, Wang K, Tu C, Wang X. Incidence and risk factors of postoperative delirium in elderly patients undergoing transurethral resection of prostate: a prospective cohort study. Neuropsychiatr Dis Treat. 2016;12:137-42.

15. Mclsaac DI, Taljaard M, Bryson GL, Beaule PE, Gagne S, Hamilton G, et al. Frailty and long-term postoperative disability trajectories: a prospective multicentre cohort study. Br J Anaesth. 2020 Nov;125(5):704-11.

16. Cheng KW, Shah A, Bazargani S, Miranda G, Cai J, Aron M, et al. Factors influencing ICU admission and associated outcome in patients undergoing radical cystectomy with enhanced recovery pathway. Urol Oncol. 2019 Sep;37(9):572 e13- e19.

17. Tanner J, Woodings $D$, Moncaster K. Preoperative hair removal to reduce surgical site infection. Cochrane Database Syst Rev. 2006 Apr 19(2):CD004122.

18. Darouiche RO, Wall MJ, Jr., Itani KM, Otterson MF, Webb AL, Carrick MM, et al. Chlorhexidine-Alcohol versus Povidone-lodine for Surgical-Site Antisepsis. N Engl J Med. 2010 Jan 7;362(1):18-26.

19. Wolf JS, Jr., Bennett CJ, Dmochowski RR, Hollenbeck BK, Pearle MS, Schaeffer AJ. Best practice policy statement on urologic surgery antimicrobial prophylaxis. J Urol. 2008 Apr;179(4):1379-90.

20. Eid JF, Wilson SK, Cleves M, Salem EA. Coated implants and "no touch" surgical technique decreases risk of infection in inflatable penile prosthesis implantation to 0.46\%. Urology. 2012 Jun;79(6):13105 .

21. Mandava SH, Serefoglu EC, Freier MT, Wilson SK, Hellstrom WJ. Infection retardant coated inflatable penile prostheses decrease the incidence of infection: a systematic review and meta-analysis. J Urol. 2012 Nov;188(5):1855-60.

22. Burchardt M, Burchardt T, Baer L, Kiss AJ, Pawar RV, Shabsigh A, et al. Hypertension is associated with severe erectile dysfunction. J Urol. 2000 Oct;164(4):1188-91.

23. El-Sakka Al, Morsy AM, Fagih $\mathrm{BI}$, Nassar AH. Coronary artery risk factors in patients with erectile dysfunction. J Urol. 2004 Jul;172(1):251-4.

24. Stanford JL, Feng Z, Hamilton AS, Gilliland FD, Stephenson RA, Eley JW, et al. Urinary and sexual function after radical prostatectomy for clinically localized prostate cancer: the Prostate Cancer Outcomes Study. JAMA. 2000 Jan 19;283(3):354-60.

25. Awad SF, O'Flaherty M, El-Nahas KG, Al-Hamaq AO, Critchley JA, Abu-Raddad LJ. Preventing type 2 diabetes mellitus in Qatar by reducing obesity, smoking, and physical inactivity: mathematical modeling analyses. Popul Health Metr. 2019 Dec 30;17(1):20.

26. Henry GD, Karpman E, Brant W, Christine B, Kansas BT, Khera M, et al. The Who, How and What of Real-World Penile Implantation in 2015: The PROPPER Registry Baseline Data. J Urol. 2016 Feb;195(2):427-33.

27. Benvenuti F, Boncinelli L, Vignoli GC. Male sexual impotence in diabetes mellitus: vasculogenic versus neurogenic factors. Neurourol Urodyn. 1993;12(2):145-51; discussion 52.

28. Krane RJ, Goldstein I, Saenz de Tejada I. Impotence. N Engl J Med. 1989 Dec 14;321(24):1648-59. 
29. Raghavan S, Vassy JL, Ho YL, Song RJ, Gagnon DR, Cho K, et al. Diabetes Mellitus-Related All-Cause and Cardiovascular Mortality in a National Cohort of Adults. J Am Heart Assoc. 2019 Feb 19;8(4):e011295.

30. Taussig AS, Hurst JW, Ambrose SS, Sewell CW. Massive prostatic infarction following aortocoronary bypass surgery: a report of two cases. Clin Cardiol. 1984 Feb;7(2):113-6.

31. Parlaktas BS, Naseri E, Uluocak N, Elalmis AO, Erdemir F, Etikan I. Comparison of the effects of onpump versus off-pump coronary artery bypass surgery on serum prostate-specific antigen levels. Int J Urol. 2006 Mar;13(3):234-7.

32. Coker C, Sherwood RA, Crayford T, Saadeh F, Mulvin D, Brakenbury E, et al. Ischemic damage to the prostate during cardiac surgery: a clinical model. Prostate. 1997 Jul 1;32(2):85-8.

33. Chang Y, Kim JH, Noh JW, Cho YS, Park HJ, Joo KJ, et al. Prostate-Specific Antigen Within the Reference Range, Subclinical Coronary Atherosclerosis, and Cardiovascular Mortality. Circ Res. 2019 May 10;124(10):1492-504.

34. Yeap BB, Araujo AB, Wittert GA. Do low testosterone levels contribute to ill-health during male ageing? Crit Rev Clin Lab Sci. 2012 Sep-Dec;49(5-6):168-82.

35. Araujo AB, Dixon JM, Suarez EA, Murad MH, Guey LT, Wittert GA. Clinical review: Endogenous testosterone and mortality in men: a systematic review and meta-analysis. J Clin Endocrinol Metab. 2011 Oct;96(10):3007-19.

36. Corona G, Rastrelli G, Monami M, Guay A, Buvat J, Sforza A, et al. Hypogonadism as a risk factor for cardiovascular mortality in men: a meta-analytic study. Eur J Endocrinol. 2011 Nov;165(5):687-701.

37. Ruige JB, Mahmoud AM, De Bacquer D, Kaufman JM. Endogenous testosterone and cardiovascular disease in healthy men: a meta-analysis. Heart. 2011 Jun;97(11):870-5.

38. Sharma R, Oni OA, Gupta K, Chen G, Sharma M, Dawn B, et al. Normalization of testosterone level is associated with reduced incidence of myocardial infarction and mortality in men. Eur Heart J. 2015 Oct 21;36(40):2706-15.

39. Snyder PJ, Bhasin S, Cunningham GR, Matsumoto AM, Stephens-Shields AJ, Cauley JA, et al. Effects of Testosterone Treatment in Older Men. N Engl J Med. 2016 Feb 18;374(7):611-24.

40. Cheetham TC, An J, Jacobsen SJ, Niu F, Sidney S, Quesenberry CP, et al. Association of Testosterone Replacement With Cardiovascular Outcomes Among Men With Androgen Deficiency. JAMA Intern Med. 2017 Apr 1;177(4):491-9.

41. Vigen R, O'Donnell Cl, Baron AE, Grunwald GK, Maddox TM, Bradley SM, et al. Association of testosterone therapy with mortality, myocardial infarction, and stroke in men with low testosterone levels. JAMA. 2014 Nov 6;310(17):1829-36.

42. Jones TH, Channer KS. Deaths and cardiovascular events in men receiving testosterone. JAMA. 2014 Mar 5;311(9):962-3.

43. Morgentaler A, Traish A, Kacker R. Deaths and cardiovascular events in men receiving testosterone. JAMA. 2014 Mar 5;311(9):961-2. 
44. Raynor MC, Smith A, Vyas SN, Selph JP, Carson CC, 3rd. Dorsal penile nerve block prior to inflatable penile prosthesis placement: a randomized, placebo-controlled trial. J Sex Med. 2012 Nov;9(11):2975-9.

45. Xie D, Nicholson M, Azaiza M, Gheiler V, Lopez I, Nehrenz GM, et al. Effect of operative local anesthesia on postoperative pain outcomes of inflatable penile prosthesis: prospective comparison of two medications. Int J Impot Res. 2018 Jun;30(3):93-6.

\section{Tables}

\section{Table -1: Demographic Characteristic}




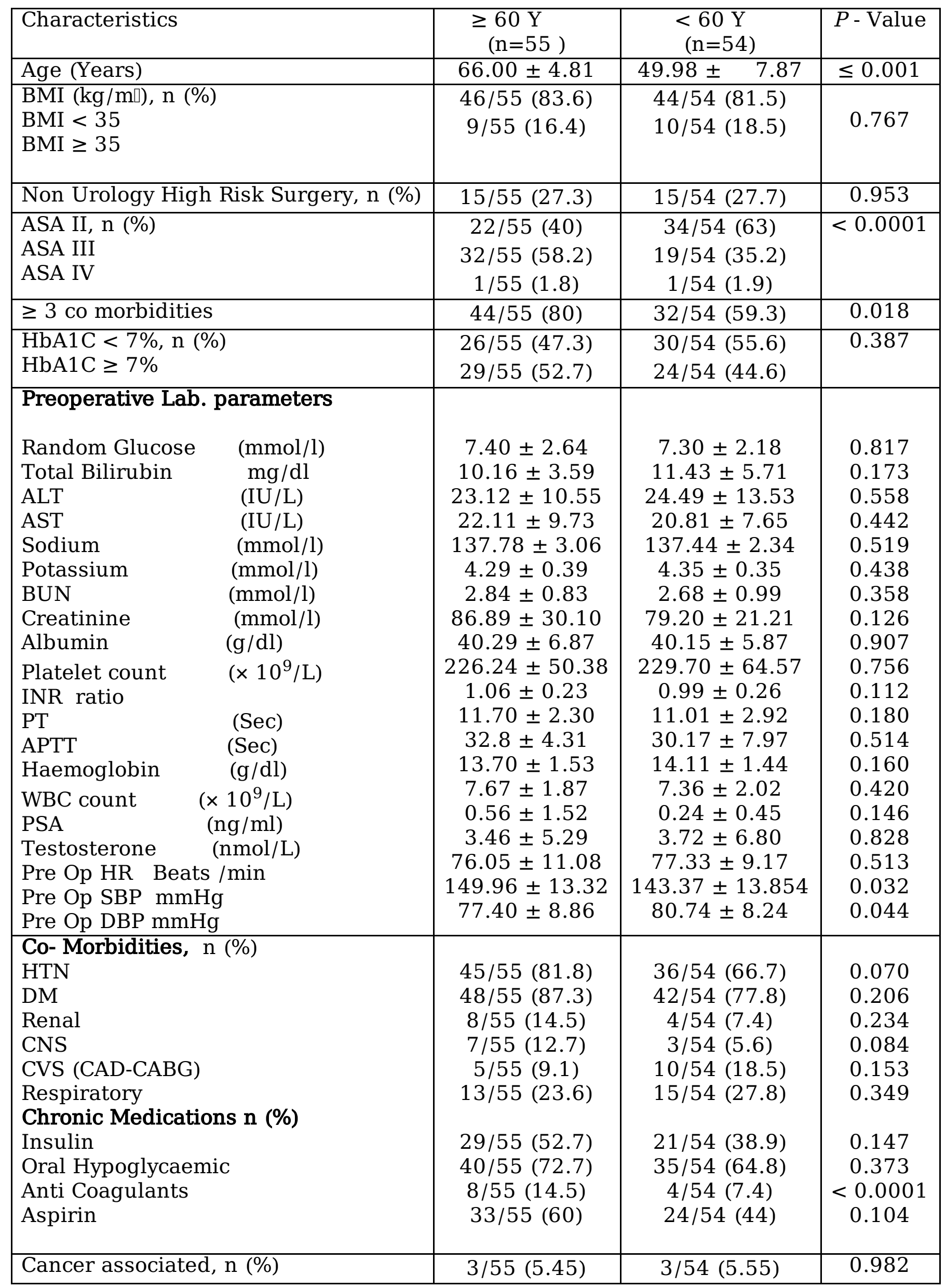


Values are either mean \pm SD or number and percentage, n (\%). $P \square 0.05$ considered statistically significant.

Abbreviations: Body mass index (BMI ); American Society of Anaesthesiologists (ASA); laboratory (Lab) ; Alanine Aminotransferase (ALT) ; Aspartate Aminotransferase (AST) ; Blood Urea Nitrogen (BUN) ; International Normalized Ratio (INR) ; Prothrombin Time (PT) ; Activated Partial Thromboplastin Time (APTT) ; White blood cells (WBCs); prostate specific antigen (PSA) ;Hypertension (HTN) ; Diabetes Mellitus (DM); central nervous system (CNS); cardiovascular system (CVS); coronary artery disease (CAD); coronary artery bypass grafting (CABG); glycated haemoglobin percentage (HbA1C \%).

Table -2: Intra Operative and Post Operative Variables of patients underwent penile prosthesis surgery.

\begin{tabular}{|c|c|c|c|}
\hline Characteristics & $\begin{array}{l}\geq 60 Y \\
(n=55)\end{array}$ & $\begin{array}{l}<60 \mathrm{Y} \\
(\mathrm{n}=54)\end{array}$ & $P$ - Value \\
\hline Type of Anesthesia n (\%) & & & \\
\hline & $50 / 55(90.9 \%)$ & $50 / 54(92.6 \%)$ & 0.483 \\
\hline GA & 2/55 (3.6 \%) & $3 / 54(5.6 \%)$ & 0.636 \\
\hline CSE & $3 / 55(5.5 \%)$ & $1 / 54(1.9 \%)$ & 0.044 \\
\hline Total crystalloids / ml & $1198.18 \pm 71.96$ & $1343.20 \pm 70.63$ & 0.153 \\
\hline Total colloids / ml & $53.92 \pm 18.94$ & $86.73 \pm 28.75$ & 0.343 \\
\hline Blood loss /ml & $66.42 \pm 9.50$ & $65.09 \pm 12.52$ & 0.933 \\
\hline Surgical Complications n (\%) & & & \\
\hline Bleeding & 1/55 (3.6 \%) & 0 & 0.310 \\
\hline Re Exploration & & $2 / 54(3.7 \%)$ & 0.157 \\
\hline Wound Infection / dehiscence & $4 / 55(7.3 \%)$ & 0 & 0.526 \\
\hline Prosthesis infection & $1 / 55(3.6 \%)$ & $3 / 54(5.6 \%)$ & 0.570 \\
\hline Device failure & 0 & $2 / 54(3.7 \%)$ & 0.157 \\
\hline Glans ischemia & 0 & $1 / 54(1.9 \%)$ & 0.320 \\
\hline PO HR & $71.80 \pm 8.99$ & $74.17 \pm 8.30$ & 0.156 \\
\hline PO SBP & $131.36 \pm 13.78$ & $127.15 \pm 13.98$ & 0.116 \\
\hline PO DBP & $71.25 \pm 8.19$ & $74.46 \pm 8.94$ & 0.053 \\
\hline LOS / days means \pm SD (Range) & $1.55 \pm 2.04(1-10)$ & $1.13 \pm 0.48(1-3)$ & 0.146 \\
\hline Survival PO days & $1419.9 \pm 831.34$ & $1301.1 \pm 692.29$ & 0.419 \\
\hline Death n (\%) & $2 / 55(3.6)$ & $2 / 54(3.7)$ & 0.665 \\
\hline
\end{tabular}

Values are either mean \pm SD or number and percentage, $\mathrm{n}(\%) . \quad P \square 0.05$ considered statistically significant.

\section{Abbreviations:}

GA; general anaesthesia; SA; spinal anaesthesia; CSE; combined spinal epidural; PO; postoperative; HR; heart rate; SBP ; systolic blood pressure; DBP; diastolic blood pressure ; LOS; length of hospital stay and PO; postoperative.

Table-3: Clinical characteristics and perioperative outcome of dead patients underwent penile prosthesis surgery. 


\begin{tabular}{|c|c|c|c|c|}
\hline Factor & Patient -1 & Patient -2 & Patient -3 & Patient -4 \\
\hline Age (Year) & 63 & 62 & 56 & 44 \\
\hline BMI $(\mathrm{kg} / \mathrm{m} \square)$ & 28 & 21 & 27 & 27 \\
\hline $\begin{array}{l}\geq 3 \mathrm{Co} \\
\text { norbidities }\end{array}$ & $\begin{array}{c}\text { DM, } \\
\text { HTN,IHD, } \\
\text { Aspirin }\end{array}$ & $\begin{array}{c}\text { HTN, COPD, Emphysema, } \\
\text { CAD,AF, abdominal aortic } \\
\text { aneurysm, CNS stroke, } \\
\text { ANTI-coagulants }\end{array}$ & $\begin{array}{l}\text { DM, HTN, } \\
\text { CAD PCI, } \\
\text { COPD, } \\
\text { smoker, } \\
\text { CKD } \\
\end{array}$ & $\begin{array}{c}\text { DM, } \\
\text { Hypercholesterolemia, } \\
\text { DVT vascular history, } \\
\text { diabetic retinopathy. }\end{array}$ \\
\hline ASA Status & II & $\overline{\text { III }}$ & III & III \\
\hline Pre op EF & 57 & 57 & 67 & 57 \\
\hline $\begin{array}{l}\text { Pre-PSA N: }(0- \\
1 \mathrm{ng} / \mathrm{ml})\end{array}$ & 0.55 & 1.97 & 1.37 & 0.13 \\
\hline $\begin{array}{l}\text { Pre- } \\
\text { estosterone } \\
\text { N: }(10.4-35 \\
\text { amol/L) }\end{array}$ & 7.6 & 9.5 & 9.17 & 8.31 \\
\hline $\begin{array}{l}\text { Pre- HbA1C \% } \\
\text { N: }(4.8-6 \%)\end{array}$ & 7.9 & 5.7 & 8.9 & 7.6 \\
\hline $\begin{array}{l}\text { Surgical } \\
\text { Jomplications }\end{array}$ & 0 & 0 & $\begin{array}{l}\text { Prosthesis } \\
\text { infection }\end{array}$ & 0 \\
\hline $\begin{array}{l}\text { Non Urology } \\
\text { Surgery }\end{array}$ & $\begin{array}{l}\text { Open } \\
\text { Heart - } \\
\text { firearm }\end{array}$ & $\begin{array}{l}\text { abdominal aortic } \\
\text { aneurysm }\end{array}$ & $\begin{array}{l}\text { Aorto bi } \\
\text { femoral } \\
\text { bypass }\end{array}$ & $\begin{array}{l}\text { Multiple eye retinal } \\
\text { surgeries }\end{array}$ \\
\hline $\begin{array}{l}\text { admission/days } \\
\text { admis }\end{array}$ & 0 & 0 & 0 & 0 \\
\hline LOS / days & 1 & 1 & 1 & 1 \\
\hline $\begin{array}{l}\text { Zause of } \\
\text { Death }\end{array}$ & $\begin{array}{c}\text { Acute } \\
\text { heart } \\
\text { failure, } \\
\text { DM,HTN }\end{array}$ & $\begin{array}{c}\text { Sequence of CNS stroke, } \\
\text { sepsis, IHD }\end{array}$ & $\begin{array}{c}\text { Acute } \\
\text { bilateral } \\
\text { LL } \\
\text { ischemia } \\
\text { and } \\
\text { gangrene }\end{array}$ & $\begin{array}{c}\text { Acute heart failure in } \\
\text { DM - DVT vascular } \\
\text { history }\end{array}$ \\
\hline $\begin{array}{l}\text { Survivals PO } \\
\text { lays }\end{array}$ & 90 & 1354 & 2555 & 1670 \\
\hline
\end{tabular}

Abbreviations: BMI; body mass index; ASA; American Society of Anaesthesiologists; EF; ejection fraction; ICU; intensive care unit; LOS; length of stay; PO; postoperatively; PSA; prostate specific antigen; HbA1C; glycated haemoglobin percentage. 
4. Univariate and multivariate analysis with respect to overall survival in patients after э prosthesis surgery.

\begin{tabular}{|c|c|c|c|c|c|c|}
\hline \multirow[b]{3}{*}{ actor } & \multicolumn{3}{|c|}{ Univariate } & \multicolumn{3}{|c|}{ Multivariate } \\
\hline & \multicolumn{6}{|c|}{$\mathrm{P}$} \\
\hline & $\mathrm{HR}$ & $(95 \% \mathrm{CI})$ & Value & HR & $(95 \% \mathrm{CI})$ & $P$ Value \\
\hline \multicolumn{7}{|c|}{ (0.904 - } \\
\hline ierative SBP & 0.948 & $0.994)$ & 0.028 & & & \\
\hline \multicolumn{4}{|l|}{ ierative } & 1.174 & (1.007 - & 0.040 \\
\hline sterone & 1.125 & $(1.005-1.258)$ & 0.040 & & 1.368) & \\
\hline \multicolumn{7}{|l|}{ əviations: } \\
\hline
\end{tabular}

\section{Figures}




\section{Survival Functions}

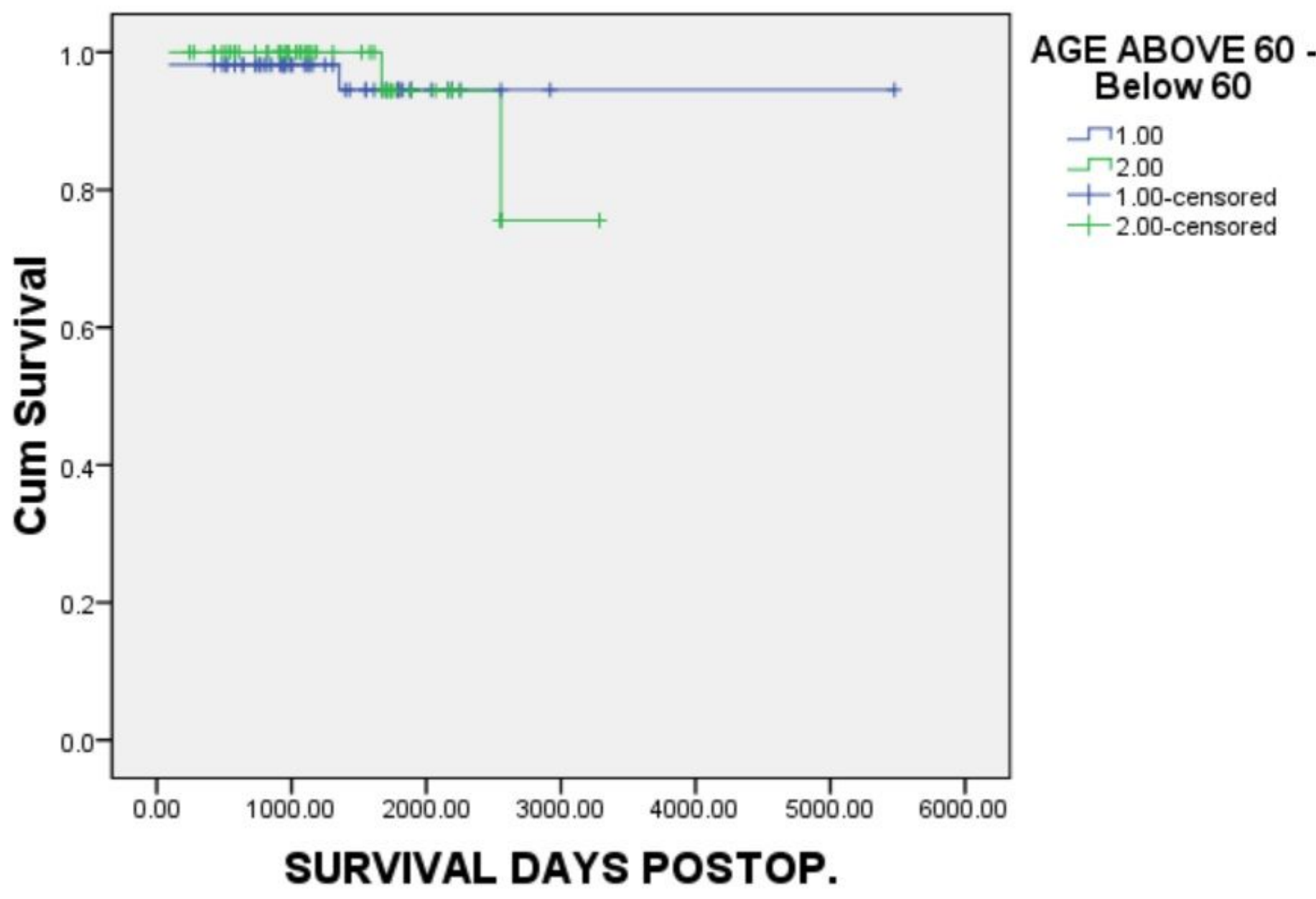

Figure 1

Cumulative survival for patients underwent penile prosthesis surgery. Group I represented $\geq 60$ years old patients and group II represented $<60$ years old patients. 